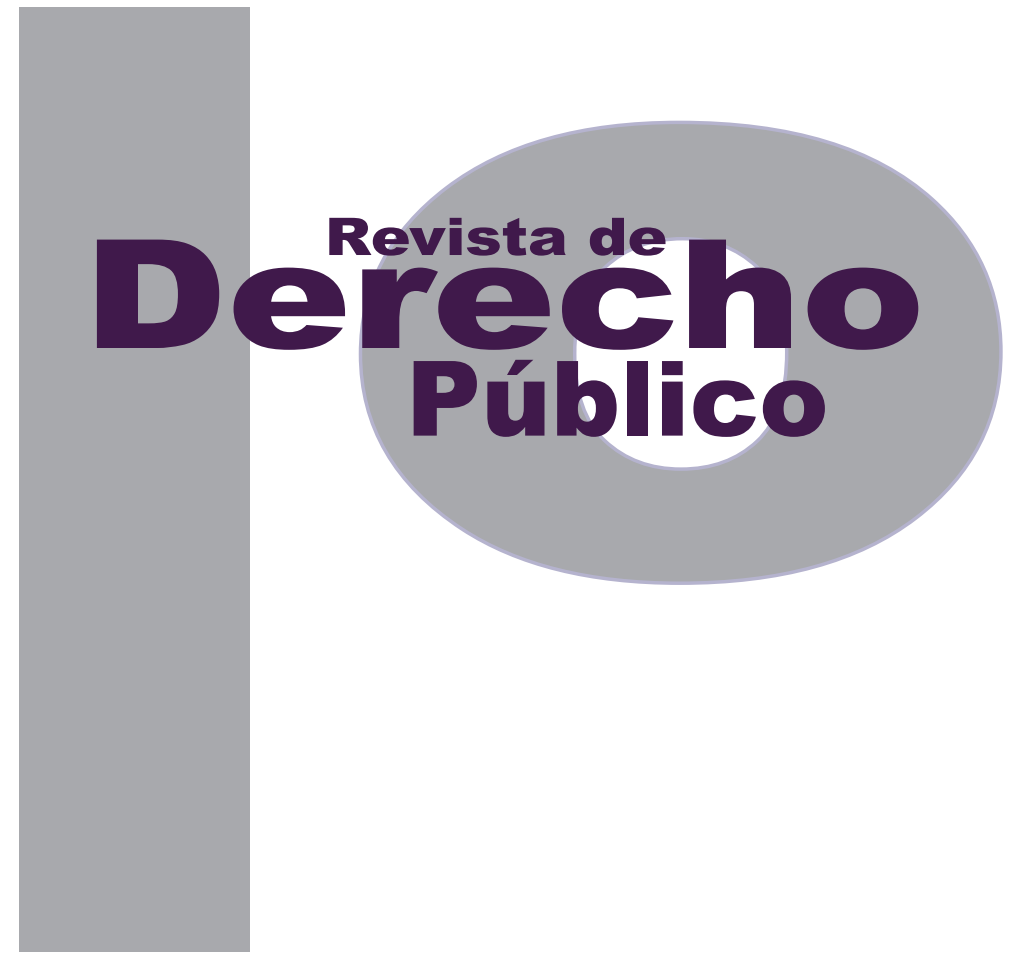

\title{
DEFENSA DEL DERECHO A LA LIBRE CIRCULACIÓN INTERNACIONAL
}

\author{
FERNANDO GALEANO
}

Universidad de los Andes

Facultad de Derecho

Revista de Derecho Público N. ${ }^{\circ} 28$

Enero - Junio de 2012. ISSN 1909-7778 


\title{
Defensa del derecho a la libre circulación internacional
}

\author{
Fernando Galeano ${ }^{1}$
}

\section{RESUMEN}

El estatus de "nacional" es la clave que habilita la protección efectiva del ser humano en el orden jurídico internacional. El individuo que está privado de derechos ciudadanos también lo está de derechos humanos. Los extranjeros, y en el peor de los casos indocumentados, intentan cruzar violentas fronteras en busca de mejores oportunidades de vida. En oposición al esquema jurídico vigente que rotula negativamente al migrante, defiendo la apertura de las fronteras, convencido de que el flujo libre de personas es indispensable como condición de posibilidad para que comiencen a entablarse relaciones sociales que progresivamente

\section{ABSTRACT}

The nationality status is key to guarantee the protection of a human being in the international legal system. Denying someone's rights as a citizen would also imply denying his human rights. Foreigners, in a desperate attempt to look for better opportunities, often risk their own lives by crossing international boarders in an unsafe manner. In contrary to the current legal scheme which portraits immigrants in a negative and alienating way, I advocate to open international boarders as an essential condition to foster strong social integration and relationships that will progressively derive in authentic legal reforms, materialized in public law regulations,

Abogado con opción en filosofía de la Universidad de los Andes. Ha sido miembro investigador del Observatorio Constitucional y del Observatorio de Discriminación Racial. Actualmente, se desempeña como profesor auxiliar del área de derecho público del Consultorio Jurídico de la Universidad de los Andes. El autor agradece las guías, correcciones y consejos brindados por la profesora Beatriz Sánchez en la elaboración de este documento. f.galeano81@uniandes.edu.co 
deriven en auténticos compromisos jurídicos, and the establishment of a new global model of materializados en normas de derecho público, y solidarity.

en la configuración de un nuevo modelo de solidaridad global.

Keywords: Free movement, hospitality, solidarity.

Palabras clave: Libertad de circulación, hospitalidad, solidaridad. 


\section{SUMARIO}

Introducción - I. CONTEXTO - A. Ciudadanía - B. La tensión subyacente al concepto clásico de ciudadanía - II. PROTECCIÓN OFRECIDA AL MIGRANTE POR EL SISTEMA UNIVERSAL DE DERECHOS HUMANOS - A. La dignidad como fundamento central del sistema de derechos humanos - B. La libertad de circulación en el Derecho Internacional de los Derechos Humanos - C. Catálogo de derechos del migrante - 1. Categorías de migrantes y trato diferenciado - 2. Ensanchamiento de la protección de los derechos de los migrantes - 2.1. Obligación de protección del Estado a toda persona en su territorio o bajo su jurisdicción - 2.2. Protección especial a los residentes de larga data - 2.3. Xenofobia como manifestación contemporánea del trato discriminatorio - III. LA HOSPITALIDAD UNIVERSAL - A. El colonialismo es incompatible con un orden global en paz - B. Las personas inevitablemente existen en interdependencia dado el mundo compartido en el que viven - C. La libre circulación plena como prerrequisito para la configuración de un modelo de ciudadanía global - 1. El modelo clásico de nación étnica - 2. Nuevo modelo de ciudadanía solidaria - IV. CONCLUSIONES - Bibliografía. 


\section{Introducción}

En algún momento de nuestras vidas, hemos depositado enormes esperanzas en el movimiento de los derechos humanos y hemos asumido, con convicción, la defensa jurídica y política de su discurso. Solemos traducir las reivindicaciones populares al lenguaje de los derechos humanos, lo que otorga cierta autoridad moral a nuestro discurso y brinda una forma de comunicación compartida y aceptada por vastos sectores de la sociedad.

Pero, como bien advierte el profesor David Kennedy, debemos ser menos apasionados para realizar un balance real del movimiento de los derechos humanos y determinar, con objetividad, si éste es realmente parte de la solución o, por el contrario, parte del problema de la sociedad actual. En efecto, no pocas veces las promesas de emancipación se han desviado, dejando a los individuos a la deriva, bajo el manto de la soberanía inescrutable del Estado-nación. En últimas, dado que los derechos son promovidos, protegidos y exigibles principalmente en el marco de la relación entre un sujeto con respecto a su Estado, se termina, paradójicamente, fortaleciendo las competencias de los Estadosnación y su margen de acción. Podemos aseverar, incluso, que el individuo como sujeto de derechos solo concibe y experimenta la libertad en tanto que ciudadano adscrito a un Estado².

El fenómeno creciente de las migraciones es el escenario perfecto para reflexionar acerca de

2 Kennedy, David. The International Human Rights Movement: Part of the Problem? Recuperado el 18 de mayo de 2011 en http://www.law. harvard.edu/students/orgs/hrj/iss15/kennedy.shtml. esta tensión, y para realizar una aproximación crítica a la protección con vocación universalista que promete el Derecho Internacional de Ios Derechos Humanos al tiempo que, por otro lado, da su visto bueno al ejercicio soberano de los Estados para controlar celosamente sus fronteras.

\section{CONTEXTO}

De acuerdo con los cálculos de la Organización Internacional para las Migraciones (OIM), 214 millones es el número estimado de migrantes internacionales a nivel mundial ${ }^{3}$. Lo anterior nos permite concluir que hoy día, una de cada 33 personas en el mundo (3.1\%), es un migrante (mientras que en el 2000 una de cada 35 personas lo era).

En un mundo segmentado por muros que aún no caen ${ }^{4}$, el gobierno de los Estados Unidos de América, durante lo corrido de la administración de Barack Obama ha deportado alrededor de 1.1 millones de personas, más que cualquier otro Presidente desde Dwight E. Eisenhower. Ello a pesar de los elevados $\operatorname{costos}^{5}$ de tal

3 Consultado el 29 de septiembre de 2011 en http://www.iom.int/jahia/ Jahia/about-migration/facts-and-figures/lang/es.

4 De los cuales los más representativos serían: la pared que separa barrios católicos y protestantes de Belfast, Irlanda; los 250 kilómetros de cercas eléctricas, minas y un fuerte despliegue militar impiden el contacto entre habitantes de Corea del Sur y del Norte; en Nicosia, la capital de Chipre, barricadas y costales de arena marcan el límite entre la parte controlada por Turquía y el resto de la isla; el muro que levantó Estados Unidos a lo largo de su frontera con México para contener a los inmigrantes de este país; y el que Israel construyó en Cisjordania argumentando que era necesario para protegerse de los ataques de algunos palestinos.

5 "Controlling migration is costly. According to an International Organization for Migration (IOM) report, the twenty-five richest countries spend 25 to 30 billion dollars per year on the enforcement of 
procedimiento: se calcula que cada deportación cuesta aproximadamente 12.500 dólares por persona ${ }^{6}$.

En Ventimiglia, un pequeño pueblo italiano fronterizo, los inmigrantes se amontonan cerca de la estación de trenes entre cajas que hacen las veces de refugio, aguardando la posibilidad de seguir su travesía a territorios franceses. Muchos de ellos, huyendo de las revueltas árabes que sacudieron los países del norte de África, vienen en busca de trabajo o simplemente persiguen un lugar "tranquilo" donde recomenzar sus vidas. ¿Por qué Francia no puede ayudarnos? es lo que se preguntan?.

Hay una respuesta sencilla a una pregunta más bien compleja: Francia no es responsable de su suerte, en tanto que son ciudadanos de otro Estado. Por tratarse de personas nacidas en Libia, Túnez o Marruecos, no hay obligación expresa de recepción o cuidado. Su búsqueda

immigration laws (Martin 2003). These costs stem not only from controlling borders, but also from issuing visas and residence permits, prosecuting, detaining and removing undocumented migrants, carrying out labor inspections and implementing sanctions on employers, treating asylum-seekers' claims, resettling refugees, and searching for undocumented migrants. These investments in migration controls contrast with their cost-effectiveness: although it is difficult to measure their deterrence effect on potential migrants, the persistence of undocumented migration illustrates how even sophisticated forms of controls do not really stop people." Pécoud, Antoine y de Guchteneire, Paul. "International Migration, Border Controls and Human Rights: Assessing the Relevance of a Right to Mobility". Journal of Borderlands Studies, Volume 21, No. 1, 2006, p. 71.

6 Cave, Damien. "Crossing Over and Over". The New York Times. Recuperado el 2 de noviembre de 2011 en http://www.nytimes. com/2011/10/03/world/americas/mexican-immigrants-repeatedly-brave-risks-to-resume-lives-in-united-states.html?_r=1\&sq=migrants\&st= cse\&scp $=5$ \& pagewanted $=$ print

7 Giuffrida, Angela. "Tunisian Migrants Open Tensions in Europe". The New York Times. Recuperado el 10 de abril de 2011 en http://www. nytimes.com/2011/04/07/world/europe/07iht-m07-migrants.html?_r=1 $\& s q=$ migrants\&st $=c s e \& s c p=1$ \&pagewanted=print de una mejor vida, y su lucha por la democracia es aplaudida en Occidente a la distancia, pero cuando los efectos secundarios tocan las puertas de Europa, se repele a los migrantes bajo el calificativo de indocumentados o ilegales.

Pero si por un momento nos propusiéramos dejar a un lado los prejuicios y temores que retumban cada vez que se habla de migrantes y refugiados cruzando ilegalmente la frontera, miraríamos con sospecha cómo el concepto de ciudadanía ha abierto una inmensa brecha entre los nacionales adscritos a un Estado y, del otro lado, los migrantes que intentan cruzar la frontera. Mientras los primeros son sujetos plenos de derecho, los segundos únicamente son protegidos por un manto tenue de derechos humanos, y su gran reto es cumplir con los requisitos locales exigidos para adquirir la membresía que los identifique formalmente como ciudadanos.

El título de "ciudadano" se ha vuelto entonces determinante para una existencia digna. Como acertadamente señala Joseph Carens "el concepto de ciudadanía imperante en las democracias liberales de occidente es el equivalente contemporáneo a los privilegios feudales, un status hereditario que determina las posibilidades que un individuo tendrá en su vida"8. Cuando observamos atentamente la lógica subyacente, el concepto restringido de ciudadanía y la exclusión del extranjero, en razón de su lugar de nacimiento, es una idea altamente cuestionable. El lugar de nacimiento y el parentesco

8 Carens, Joseph. "Aliens and Citizens: The Case for Open Borders". The Review of Politics. Vol. 49, No. 2 (1987), p. 252. Cambridge: Cambridge University Press for the University of Notre Dame du lac on behalf of Review of Politics. 
de un ser humano son criterios de clasificación arbitrarios desde un punto de vista moral ${ }^{9}$, en la medida que obedecen a contingencias de la naturaleza sobre las que el individuo afectado no tienen poder alguno de decisión, tal y como lo es el color de la piel o las destrezas físicas.

En el ámbito jurídico, la importancia de este hecho es mayúscula, ya que la obtención de una ciudadanía es determinante para acceder a un catálogo de derechos y un nivel de protección suficiente. En definitiva, la condición de ciudadanía en el orden jurídico internacional vigente es la clave que acciona la protección efectiva del ser humano. De manera que el individuo que está privado de derechos ciudadanos, también lo está de derechos humanos ${ }^{10}$.

\section{A. Ciudadanía}

Ciudadanía es un concepto denso. Para entenderlo mejor, resulta de utilidad recurrir a la profesora de ciencias jurídicas, Linda Bosniak ${ }^{11}$, quien se ha encargado de agrupar los distintos esquemas teóricos formulados para responder a la pregunta sobre la ciudadanía:

“En primer lugar, la ciudadanía se emplea usualmente en un sentido jurídico para señalar el estatus formal de pertenencia a una comunidad política. En la tradición sociológica que se inicia con T. H. Marshall, el término es utilizado

$9 \quad$ lbíd., p. 262.

10 Carrillo, Lucy. El concepto kantiano de ciudadanía. Universidad de Antioquia: Estudios Filosóficos n²4, diciembre de 2010, p. 107.

11 Ver Bosniak, Linda. "Desnacionalizando la ciudadanía”. En: Ariza, Libardo (Ed). Ciudadanía sin Nación. Bogotá: Siglo del Hombre Editores, 2010. para señalar la titularidad y el goce de derechos fundamentales en la sociedad. En la tradición cívica republicana, la ciudadanía señala un estado de participación activa en la vida de una comunidad política. Finalmente, en términos psicológicos o culturales, la noción de ciudadanía es presentada para denotar la identidad y solidaridad que una persona disfruta en la vida pública o colectiva"12.

La acepción de ciudadanía como la titularidad de ciertos derechos, será desarrollada en el segundo capítulo de este documento a la luz de los principales pactos del sistema universal de derechos humanos. Como veremos, aunque los regímenes internacionales de derechos humanos que adquirieron forma durante el periodo posterior a la segunda guerra mundial, fueron diseñados para implementar los estándares que regulan el tratamiento de los individuos ya no sólo de los ciudadanos- por parte de los Estados, persiste un déficit enorme en la protección de los no nacionales, a quienes ni siquiera se les reconoce el derecho a entrar libremente a cualquier país, salvo al suyo propio.

De acuerdo con la acepción psicológica y republicana, la ciudadanía, entendida como el establecimiento de una identidad común que permite lazos de solidaridad más estrechos entre individuos, y como la participación activa en las cuestiones públicas de una comunidad política, nos explican el por qué del empeño con que los Estados han insistido en mantener sus poderes soberanos en la regulación fronteriza. Como

\footnotetext{
12 lbíd., p. 223.
} 
bien señala Catherine Dauvergne ${ }^{13}$, el control sobre los flujos de población internacional se ha convertido en el último bastión de la soberanía de los Estados ${ }^{14}$, un campo sobre el cual los órganos estatales no están dispuestos a ceder, como sí lo han venido haciendo en otras materias, especialmente en asuntos económicos ${ }^{15}$.

En efecto, las leyes migratorias son esenciales para la construcción de una nación por cuanto, de acuerdo con la definición clásica de Estadonación, se ha considerado que todo Estado debe ejercer control efectivo sobre un conjunto de población y un territorio definido ${ }^{16}$. En este sentido, las leyes migratorias responden a esta necesidad básica de todo Estado de trazar una clara línea distintiva entre los miembros de la comunidad y aquellos otros que intentan cruzar las fronteras. Sólo en el cumplimiento cabal de esta función elemental, un Estado lograría pre-

13 Ver Dauvergne, Catherine. "Sovereignty, Migration and the Rule of Law in Global Times". The Modern Law Review Limited, 2004.

14 El análisis de la autora se concentra en los países anglosajones, pero creo que el sentido general de su reflexión se puede aplicar a otros contextos.

15 Sin embargo, esta defensa férrea de la potestad de los Estados sobre su control migratorio no es del todo coherente, muestra su mayor paradoja en el contexto presente de la globalización. Pese a que vivimos en un mundo cada vez más global, éste se ha vuelto a la vez más cerrado y represivo. En efecto, "los avances en los medios de transporte facilitan el acercamiento entre lugares y personas, al tiempo que las políticas migratorias intentan conservar las distancias, neutralizar la libertad de movimiento y controlar los desplazamientos". Ariza, Libardo y Barbero, Iker. "Estudio Preliminar". En: Ciudadanía sin nación. Bogotá: Siglo del Hombre Editores, 2010, p. 32.

16 Al respecto ver Convenio de Montevideo sobre los derechos y deberes de los Estados. 26 de diciembre de 1933 y Societé des Nations. Recueil des traités, 165 (1936), 36 ss. Anteriormente, la sentencia de 1 de agosto de 1929 del tribunal mixto germano-polaco, en el asunto de Deutsche Continental Gas Gessellschaft. El Estado polaco se había expresado ya en parecidos términos (Rec. Tam, I, 36-348), en el sentido que hay 4 elementos constitutivos de todo Estado: i- Base territorial cierta; ii- Población permanente; iii- Organización política; iv- Independencia. sentarse ante la comunidad internacional como un auténtico sujeto de derecho global.

Es más, de acuerdo con autores de la corriente comunitarista como Michael Walzer, la pertenencia es el derecho original de todo individuo en una comunidad liberal. La cuestión sobre la pertenencia debe ser resuelta antes de plantearse pregunta alguna sobre lo justo y lo injusto ${ }^{17}$. En razón de lo anterior, todo Estado aceptaría como natural distinguir entre aquellos que gozan de una "membresía nacional" y todos los otros, frente a los cuales ni siquiera deberíamos formular consideraciones en derecho o de justicia.

\section{B. La tensión subyacente al concepto clásico de ciudadanía}

Dada la importancia social, política y jurídica del concepto de ciudadanía, y del proyecto de homogenización cultural de los pueblos referidos anteriormente, los Estados defienden celosamente su integridad territorial. Al otro lado de la cerca, las fronteras son agresivas alambradas de púas con alarmas, cemento, soldados, perros guardianes, patrullas móviles y sistemas de rastreo militar. Tal despliegue de fuerza y de violencia debe hacernos sospechar de la necesidad y la proporcionalidad de estas medidas en contra del migrante. En últimas, deberíamos cuestionarnos: ¿qué justifica tan excesivo uso de la fuerza? ${ }^{18}$

17 Walzer, Michael. Spheres of Justice: A Defense of Pluralism and Equality. New York: Basic Books, 1983. Capítulo 2.

18 Carens, Joseph. "Aliens and Citizens: The Case for Open Borders". The Review of Politics. Vol. 49, No. 2 (1987), p. 251. Cambridge: 
No podemos ignorar el valor que representa para el sistema jurídico de los Estados-nación el concepto de ciudadanía, ni tampoco desconocer el impacto que podría representar la incursión descontrolada de migrantes para la estabilidad de los pueblos. Con todo, algo merece ser revisado cuando un documento, un simple trámite administrativo (el mecanismo de visado) determina radicalmente no sólo el estatus jurídico de una persona, sino el tipo de vida y de oportunidades a las que puede aspirar ${ }^{19}$. Este "algo" es precisamente el concepto estrecho de ciudadanía, asociado exclusivamente a una identidad cultural nacional, y que se ha convertido en el principal motivo contemporáneo de discriminación. Los Estados clasifican entre sus ciudadanos y los no-ciudadanos, privando a estos últimos del goce pleno de sus derechos básicos.

\section{PROTECCIÓN OFRECIDA AL MIGRANTE POR EL SISTEMA UNIVERSAL DE DERECHOS HUMANOS}

En esta sección presento las principales conclusiones del estudio de cinco importantes instrumentos del sistema universal de protección de los derechos humanos, promovidos desde el seno de la Organización de Naciones Unidas (ONU), los cuales aportan elementos valiosos sobre la regulación de las migraciones y los derechos de

Cambridge University Press for the University of Notre Dame du lac on behalf of Review of Politics.

19 El fetiche jurídico del pasaporte y del visado cobra una importancia enorme, "de acuerdo con el cual la vida cambia y del cual depende la dignidad humana de muchas personas" (Boaventura, Santos. La globalización del derecho. Los nuevos caminos de la regulación y la emancipación. Bogotá: ILSA y Universidad Nacional, 1998, p. 147. la población migrante: (i) Declaración Universal de los Derechos Humanos; (ii) Convención internacional sobre la eliminación de todas las formas de discriminación racial; (iii) Pacto Internacional de Derechos Civiles y Políticos; (iv) Pacto Internacional de Derechos Económicos, Sociales y Culturales; y, (v) Convención internacional sobre la protección de los derechos de todos los trabajadores migratorios y de sus familias.

Como podrá advertir el lector, he excluido de manera expresa la Convención de 1951 sobre el estatuto de los refugiados, teniendo en cuenta que la lógica que regula el fenómeno de la población refugiada y solicitante de asilo ha sido considerada - de manera relativamente pacífica- distinta al tema de la migración en general. Además, el solicitante de asilo está autorizado, al menos en teoría, para entrar a cualquier Estado en busca de protección, ya sea de manera regular o irregular. En efecto, de acuerdo con lo dispuesto en el artículo 31 de la Convención de 1951 "no se impondrán sanciones por la entrada o permanencia irregular al país".

En segundo lugar, el artículo 33 consagra el principio - que ya es asumido como una regla de jus cogens- de Non Refoulement o no devolución, en virtud del cual "[n]ingún Estado Contratante podrá, por expulsión o devolución, poner en modo alguno a un refugiado en las fronteras de los territorios donde su vida o su libertad peligre por causa de su raza, religión, nacionalidad, pertenencia a determinado grupo social, o de sus opiniones políticas". Con ello queda en evidencia que la libertad de circulación, para el caso 
específico de los refugiados, tiene una regulación especial que resuelve, en parte, el tema del derecho a entrar a otros países.

\section{A. La dignidad como fundamento central del sistema de derechos humanos}

La Declaración Universal de Derechos Humanos $^{20}$ (DUDH) afirma categóricamente desde su preámbulo que "la libertad, la justicia y la paz en el mundo tienen por base el reconocimiento de la dignidad intrínseca y de los derechos iguales e inalienables de todos los miembros de la familia humana". Más adelante, la Declaración retoma la máxima de la revolución francesa, según la cual "[t]odos los seres humanos nacen libres e iguales en dignidad y derechos y, dotados como están de razón y conciencia, deben comportarse fraternalmente los unos con los otros" ${ }^{21}$. Con ello queda claro que desde un comienzo, el concepto de dignidad fue central en la fundamentación del lenguaje de los derechos humanos al interior de la Organización de Naciones Unidas.

La DUDH también incluye en su articulado una disposición que si bien resulta ambigua e incluso oscura, parece sugerir un proyecto de reforma estructural del ordenamiento global para hacer realidad las promesas de paz, seguridad y cooperación internacional. Se trata del derecho,

20 Es importante destacar cómo este instrumento surge en medio del choque ideológico entre los Estados de Occidente y los países de la Europa socialista. Pese a ello se logró pactar un acuerdo de mínimos, donde el concepto de dignidad es el punto de unión. Ver Cassese, Antonio. Los derechos humanos en el mundo contemporáneo. Barcelona: Ariel, 1993. en cabeza de cada persona "a que se establezca un orden social e internacional en el que los derechos y libertades proclamados en esta Declaración se hagan plenamente efectivos" 22 . Con lo cual se pone en evidencia el discurso universalista y altamente ambicioso que nutrió el proceso de creación de la ONU, así como la esperanza que se depositaba en sus tratados y que alentaría la búsqueda de un nuevo tipo de ciudadanía posnacional más acorde con el principio de dignidad humana.

En el año de 1965, se expide la Convención internacional sobre la eliminación de todas las formas de discriminación racial (CEDR), la cual reitera que "la dignidad y la igualdad inherentes a todos los seres humanos" han sido los fundamentos conceptuales sobre los cuales se configuró la Carta de las Naciones Unidas. Igualmente, comparte la máxima proclamada por la DUDH a partir de la cual se reconoce que "todos los seres humanos nacen libres e iguales en dignidad y derechos, y que toda persona tiene todos los derechos y libertades enunciados en la misma, sin distinción alguna, en particular por motivos de raza, color u origen nacional" 23 .

Un año después se redactaron los dos tratados más representativos del catálogo de derechos humanos en el orden universal: el Pacto Internacional de Derechos Civiles y Políticos (PIDCP) y el Pacto Internacional de Derechos Económicos, Sociales y Culturales (PIDESC). En su preámbulo común se reconoce, siguiendo el precedente fijado por la DUDH, que los

\footnotetext{
$22 \mathrm{DUDH}$, Art. 28

23 CEDR, Preámbulo
} 
"derechos se derivan de la dignidad inherente a la persona" como miembro de la familia humana. Al mismo tiempo, se proclama que el "ideal del ser humano libre en el disfrute de las libertades civiles y políticas y liberado del temor y de la miseria" demanda las condiciones necesarias que permitan a cada persona gozar de sus derechos civiles y políticos, tanto como de sus derechos económicos, sociales y culturales. Lo que remite a la noción de interdependencia de los derechos humanos.

Esta breve descripción de las consideraciones que de manera expresa encabezaron los instrumentos de protección de derechos humanos, nos permite observar cómo la dignidad humana ha sido central en la defensa jurídica de los derechos humanos, como auténticas obligaciones vinculantes para los Estados.

\section{B. La libertad de circulación en el Derecho Internacional de los Derechos Humanos.}

Aterrizando en el tema específico de estudio, el artículo 13 de la DUDH es significativo en tanto que dispone que "[t]oda persona tiene derecho a circular libremente y a elegir su residencia en el territorio de un Estado"24. EI PIDCP en su artículo 12 desarrolla esta regla y establece parámetros más concretos para regular el movimiento transfronterizo de personas.

En primer lugar, es de resaltar que el artículo introduce una clasificación adicional al concepto

24 DUDH, Art. 13. Disposición que se complementa con el derecho a tener una nacionalidad (art. 14) y con la posibilidad de buscar asilo en cualquier país (art. 14). general de migrante, ya que hace referencia a la persona que "se halle legalmente" dentro de un territorio. Como veremos más adelante, los tratados internacionales han recurrido constantemente a subclasificaciones dentro del universo de los migrantes, lo que conlleva, a su vez, a un trato diferenciado.

A partir de estas normas ${ }^{25}$, podemos concluir que los instrumentos de derechos humanos señalan que cada individuo es libre de salir de su país, pero no tiene derecho alguno a ingresar a cualquier otro, salvo al suyo propio, pues la admisión está sujeta a los requisitos y criterios que implemente autónomamente cada Estado receptor $^{26}$. Dicha regla ha sido denunciada por haber formulado un derecho incompleto ${ }^{27}$, puesto que aboga por el derecho a emigrar pero calla respecto a la obligación de los Estados de aceptar la inmigración.

En concordancia con dicha limitación, el Comité de Derechos Humanos ha aceptado que el Pacto no reconoce a los extranjeros el derecho a entrar en el territorio de otro Estado. Por el contrario, "la cuestión de si un extranjero se encuentra

25 Ver DUDH, art. 13; PIDCP, art. 12 y Convención internacional sobre la protección de los derechos de todos trabajadores migratorios y de sus familias. art. 8. En el mismo sentido, el artículo 1 del Convenio de La Haya de 1930, relativo a los conflictos de leyes sobre nacionalidad, estipula que los Estados son libres a la hora de establecer los criterios de concesión de la nacionalidad a los extranjeros.

Comité de Derechos Humanos, Observación General No. 27 de 1999.

"For these migrants, freedom of movement is only half a right because it privileges the states right over the individual's. Including the state's right to pass laws to exclude her or him. It does not privilege the individuals rigth over the state, including her or his right to demand entry (...) Plainly, the conferment of such a right is practically meaningless unless liberally interpreted." Satvinder, S. Juss. "Free Movement and the world order". International Journal of Refugee Law, vol. 16, No. 3, p. 293. 
‘legalmente’ dentro del territorio de un Estado es una cuestión regida por el derecho interno, que puede someter a restricciones la entrada de un extranjero al territorio de un Estado" 28.

\section{Catálogo de derechos del migrante}

Para analizar la manera como los instrumentos internacionales protegen los derechos de los migrantes una vez éstos han cruzado las fronteras, considero pertinente explicar en primer lugar las restricciones al goce pleno de los derechos, a partir de las categorías que se han creado en los diversos tratados, que ya no hablan de manera universal de "toda persona humana", sino que han introducido subdivisiones que conllevan un trato claramente diferenciado entre la población migrante; luego haré referencia a los avances que, en mi opinión, han impulsado los comités de seguimiento de los tratados a través de las observaciones generales, para cerrar esta brecha en la relación entre nacionales y migrantes.

\section{CATEGORÍAS DE MIGRANTES Y TRATO DIFERENCIADO}

A diferencia del lenguaje empleado en la DUDH que se refería de manera genérica a "todo ser humano", el desarrollo convencional posterior se ha caracterizado por imponer una nutrida clasificación entre: nacionales, extranjeros en situación regular, extranjeros en situación irregular, refugiados, trabajadores migrantes en situación regular y trabajadores migrantes en

28 Comité de Derechos Humanos. Observación general No. 27 de 1999. Ver también Comité de Derechos Humanos. Observación general No. 15 de 1986 situación irregular. Todos estos términos han entrado a ocupar el lugar en el que anteriormente solo se empleaba el concepto universal de "todo ser humano".

Los instrumentos convencionales referidos anteriormente han empleado una serie de distinciones de acuerdo con el status migratorio de la persona, lo que resulta determinante a la hora de identificar el catálogo de derechos que, convencionalmente, puede exigir un individuo frente al Estado receptor. En el anexo 1 presento un cuadro que resume la clasificación de la población migrante, diseñada en los instrumentos convencionales de protección, y los derechos que pueden exigir según las categorías en que se encuentran.

La principal clasificación que se puede evidenciar en algunos de los instrumentos ${ }^{29}$ es la distinción entre el migrante en situación regular y el migrante en situación irregular. De acuerdo con lo preceptuado por el Comité de Derechos Humanos, cuando hablamos de migrante irregular debemos entender que hacemos referencia a "todo aquel que ha entrado a un Estado sin el cumplimiento de las normas legales, o que habiendo entrado en forma legal, su situación se ha vuelto irregular por permanecer en el país de acogida sin satisfacer las exigencias del derecho local"30. Por oposición, aquel migrante que ha ingresado al territorio de un Estado, siguiendo los procedimientos establecidos y mientras

\footnotetext{
29 Principalmente, el Pacto Internacional de Derechos Civiles y Políticos, y la Convención internacional sobre la protección de los derechos de todos los trabajadores migratorios y de sus familias.
} 
su residencia también se ajuste a las normas locales, se tendrá como un migrante en situación regular. Luego, es función del derecho interno decidir cuándo un extranjero se encuentra 'regular' o 'Iegalmente' en el territorio del Estado miembro ${ }^{31}$.

Así, en el primer nivel del sistema diseñado dentro del Pacto Internacional de Derechos Civiles y Políticos, encontramos la categoría del migrante irregular o indocumentado. Debido a su condición irregular, la protección a la que está obligado el Estado firmante es precaria. El migrante irregular o clandestino no sólo no podrá moverse por el territorio en busca de una residencia estable, sino que está expuesto constantemente a ser expulsado de forma arbitraria o, al menos, sin sujeción a los principios básicos del debido proceso. Más aún, el reconocimiento de derechos al migrante regular es, en todo caso, claramente inferior a la protección brindada al nacional, para quien el PIDCP dispone el mayor catálogo de derechos puesto que incluye aspectos fundamentales como la participación en la dirección de los asuntos públicos y el derecho a votar y a ser elegido 32 .

Podemos imaginarnos entonces la clasificación que subyace en el PIDCP como una pirámide en cuya base están los migrantes en situación irregular, le siguen los extranjeros en situación regular, y en la cima encontramos a los nacionales. La concesión de derechos opera, sin embargo, de manera inversa, pues para la base se ha consagrado tan sólo unos mínimos, mientras

31 Comité de Derechos Humanos. Observación General No. 27 de 1999.

32 PIDCP, art. 25. que la cima goza de los derechos tanto de los extranjeros en situación irregular o regular, así como de unos derechos exclusivos, referentes a la participación política. Derechos estos que sin duda resultan de crucial importancia para la plena vida individual y en comunidad.

En el caso del Pacto Internacional de Derechos Económicos, Sociales y Culturales, en el último parágrafo del artículo 2 se consagra una especie de "carta en blanco" mediante la cual el PIDESC faculta a los "países en desarrollo" a decidir la forma en que cumplirán las obligaciones adquiridas respecto a los no nacionales bajo su jurisdicción. No hay mandato específico alguno, sino una simple exhortación a los Estados miembros para que tengan en cuenta tanto los derechos humanos como la capacidad económica del país, al decidir la suerte de los no nacionales en su jurisdicción. Ante esta indeterminación, es preciso recurrir a lo expuesto por su Comité de seguimiento.

El Comité de Derechos Económicos, Sociales y Culturales (Comité DESC) señaló que si bien “el Pacto contempla una realización paulatina y tiene en cuenta las restricciones derivadas de la limitación de los recursos con que se cuenta, también impone varias obligaciones con efecto inmediato" ${ }^{33}$. Especialmente significativo resulta que una de las obligaciones con efecto inmediato que emanan directamente del PIDESC "consiste en que los Estados se comprometen a garantizar que los derechos pertinentes se ejercerán sin discriminación".

33 Comité de Derechos Económicos, Sociales y Culturales. Observación general No. 3 de 1990. 
En el año 2009, el Comité DESC ${ }^{34}$ encaró a profundidad el desafío de la discriminación en el goce de los derechos sociales y señaló con preocupación que la discriminación socavaba la realización de los derechos económicos, sociales y culturales de un vasto porcentaje de la población mundial. Precisamente, advirtió que el "origen nacional" es uno de los motivos prohibidos de discriminación, el cual ha sido auspiciado por históricas y contemporáneas formas de diferenciación. ${ }^{35}$

En respuesta, el Comité defiende la idea según la cual la nacionalidad no debería impedir el acceso a los derechos conferidos convencionalmente. Por ejemplo, todos los niños dentro de un Estado, incluyendo aquellos con el estatus de indocumentados, tienen derecho a recibir educación, acceso a una alimentación adecuada y a un servicio de salud asequible. Siendo así, "el Convenio aplica a todas las personas incluyendo los no-nacionales, tales como refugiados, buscadores de asilo, personas sin Estado, trabajadores migrantes y víctimas de la trata internacional de personas, sin tener en cuenta su documentación y condición legal." ${ }^{36}$

La Convención internacional sobre la protección de los derechos de todos los trabajadores migratorios y de sus familias, por su lado, deja en claro que la protección de mínimos al trabajador irregular no implica la regularización de su situaComité de Derechos Económicos, Sociales y Culturales. Observación general No. 20 de 2009.

35 Ibid.

36 Ibíd. ción ${ }^{37}$, y que nada de lo dispuesto en el articulado se puede entender que afecte la autonomía del Estado para establecer los criterios que rigen la admisión de trabajadores migratorios $y$ de sus familiares ${ }^{38}$. Por el contrario, la lógica subyacente es que la comunidad internacional debe combatir efectivamente y desincentivar el flujo migratorio irregular, y por ello las garantías de derechos mínimos no se puede entender como una imposición que limite el accionar del Estado en su política migratoria.

Como se observa en el anexo 1, la Convención traza una evidente separación entre los derechos que puede exigir un trabajador migrante irregular frente a aquellos más amplios en cabeza del trabajador migrante en situación regular. El articulado consagra entonces un conjunto de derechos mínimos en cabeza de cualquier trabajador extranjero (derecho a la vida, derecho de asociación y prohibición de tortura, entre otros) independiente de su estatus migratorio. Sin embargo, es evidente también que la protección es bastante más robusta para el trabajador que tiene su documentación migratoria en orden.

Ello preocupa cuando se concede sólo al migrante regular derechos tan importantes como la unidad familiar (art. 44) y el derecho a unas condiciones de trabajo y de vida de los trabajadores migratorios y sus familiares de acuerdo con la dignidad humana (art. 70). Si la cláusula

37 Convención internacional sobre la protección de los derechos de todos los trabajadores migratorios y de sus familias, art. 35.

38

Convención internacional sobre la protección de los derechos de todos los trabajadores migratorios y de sus familias, art. 79 . 
general de trato digno se restringe al trabajador regular, ¿qué tipo de protección es la que queda para el trabajador que ha ingresado incumpliendo los requisitos fronterizos?

En resumen, no se ha logrado alcanzar una codificación general de los derechos humanos de los migrantes. Esta población es abordada de manera fragmentada por varios instrumentos convencionales, que no siempre hacen alusión expresa a la condición de los migrantes ${ }^{39}$. En líneas generales, los Pactos revisados confieren varios derechos civiles importantes, como el derecho a la vida, la prohibición de tratos inhumanos o degradantes, la prohibición de esclavitud, así como las libertades clásicas de opinión, pensamiento y religión.

Sin embargo, el déficit en la protección es manifiesto en otros aspectos de vital importancia, como en la libertad de movimiento, con respecto a la cual sólo se garantiza el derecho a salir de cualquier país y a entrar al propio. Los derechos políticos se confieren, a su vez, exclusivamente a los nacionales, quienes se consideran son los únicos que deben participar y ocuparse de la cuestión pública. Respecto a los derechos sociales, el articulado deja al arbitrio de los países en desarrollo reconocer los derechos prestacionales a los extranjeros, según sus capacidades.

Bajo este esquema jurídico que clasifica y rotula al migrante, pareciera que la invitación -más bien, la única alternativa - que deja el sistema internacional de derechos humanos a esta

39 Fitzpatrick, Joan. "The Human Rights of Migrants". En Aleinikoff, T. Alexander y Chetail, Vincent (eds.). Migration and International Legal Norms. The Hague: Asser Press, 2003, p. 170. población, es a que hagan lo posible para ingresar legalmente a un territorio y a mantenerse en él acatando cabalmente las condiciones dispuestas por el Estado, pues una vez dentro será plenamente reconocida su dignidad inherente como ser humano, lo cual lo hará acreedor al más amplio catálogo de los derechos convencionales.

En el escenario opuesto, si la persona se atreve a cruzar las fronteras políticas sin el aval previo de los Estados, vulnerando con ello los requisitos fronterizos demarcados por la autoridad nacional, su condición se califica como "irregular" y las consecuencias son nefastas: no es sujeto pleno de derechos, por lo que algunos de sus derechos se limitan, mientras otros se omiten abiertamente ${ }^{40}$.

\section{ENSANCHAMIENTO DE LA PROTECCIÓN DE LOS DERECHOS DE LOS MIGRANTES}

Hemos visto cómo el derecho internacional general reconoce que la política migratoria es un asunto propio de la soberanía estatal. Acorde con ello, los instrumentos de protección del

40 "Desde este punto de vista, no es una casualidad que, dentro de la dogmática jurídica, la situación del extranjero y del prisionero, como sujetos jurídicos, sea relativamente la misma. En ambos casos la suspensión de los derechos de ciudadanía -por el origen nacional o por el contenido mismo de la sanción penal- determina su posición en el sistema jurídico como un todo, es su propiedad característica. En ambos casos, algunos derechos se encuentran suspendidos, otros tienen plena vigencia, y un grupo restante es susceptible de limitación en función de las circunstancias particulares de cada caso. Cada uno debe moverse en un espacio con un capital jurídico restringido: mientras el extranjero indocumentado lo hace ocultándose de la mirada policial en la sociedad y en el mercado negro, el prisionero lo hace a lo largo de los pasillos de la prisión. Las dos situaciones indican, en el mundo práctico y simbólico de la vida cotidiana, una mayor vulnerabilidad." Ariza y Barbero, Óp. cit., p. 90. 
sistema universal de derechos humanos, pese a invocar constantemente la dignidad inherente a todo ser humano, han avalado la imposición de categorías de migrantes, lo que supone un trato diferenciado que en algunos casos configura un déficit de protección a sus derechos.

No obstante lo anterior, el sistema jurídico universal también ha sido testigo del desarrollo de nuevas teorías que han ayudado a suavizar la línea divisoria entre las distintas clases de migrantes y a brindar un trato cada vez más similar con respecto a la protección de la que goza el nacional. En este punto, los protagonistas han sido los Comités ${ }^{41}$ que, encargados de realizar el seguimiento y evaluación en el cumplimiento de las obligaciones convencionales, han aprovechado el espacio de las recomendaciones u observaciones generales para expandir el alcance del compromiso de los Estados firmantes hacia la población extranjera. Quisiera ahora destacar tres avances concretos promovidos desde los Comités:

\subsection{Obligación de protección del Estado a toda persona en su territorio o bajo su jurisdicción}

El Pacto Internacional de Derechos Civiles y políticos consagra en su artículo 2 el compromiso de cada Estado "a respetar y a garantizar a todos los individuos que se encuentren en su territorio y estén sujetos a su jurisdicción los derechos reconocidos en el presente Pacto, sin distinción"42. Aspecto de vital importancia para fundamentar la protección debida a los extranjeros que, si bien no son nacionales del Estado parte, sí podrían estar dentro de su territorio o ser sujetos a su jurisdicción, haciéndolos así sujetos de derecho.

Al respecto, el Comité de Derechos Humanos, desde el año 1981, consideró necesario señalar que "el disfrute de los derechos del Pacto no se restringe a los ciudadanos de los Estados Partes, sino que debe también extenderse a todos los individuos, independientemente de su nacionalidad o de su situación apátrida, como las personas en búsqueda de asilo, los refugiados, los trabajadores migrantes y otras personas, que pueden encontrarse en el territorio o estar sometidos a la jurisdicción del Estado Parte" ${ }^{43}$.

Bajo esta interpretación expansiva, el Comité de Derechos Humanos ha insistido en que el compromiso de los Estados no se limita a sus connacionales, sino hacia toda persona que se

\footnotetext{
42 PIDCP, art. 2.

43 Comité de Derechos Humanos. Observación general No. 3 de 1981. En el mismo sentido, Observación general No. 31 de 2004.
} 
encuentre efectivamente bajo su jurisdicción. El interrogante que surge ahora es qué tipo de protección se debe al extranjero y qué tan diferente puede ser respecto a la que se brinda al nacional.

\subsection{Protección especial a los residentes de larga data}

Es de resaltar que existe una categoría de migrante que, debido al estrecho vínculo que ha podido forjar con la vida en comunidad dentro del Estado receptor, ha sido especialmente protegido. Al referirse al numeral 4 del artículo 12 del PIDCP, el Comité de Derechos Humanos, de manera sutil, parece sugerir una ampliación en el concepto de nacionalidad al acoger otro tipo de ciudadanía no formalizada.

En tal sentido sostiene que, como en el texto del numeral 4 del artículo 12 no se hace diferencia entre nacionales y extranjeros, los titulares de ese derecho sólo pueden determinarse interpretando las palabras "su propio país". Así pues, el alcance de la expresión "su propio país" es más amplio que el de "país de su nacionalidad". A saber, "no se limita a la nacionalidad en el sentido formal, es decir, a la nacionalidad recibida por nacimiento o naturalización. Comprende, cuando menos, a la persona que, debido a vínculos especiales o a pretensiones en relación con un país determinado, no puede ser considerada como un simple extranjero" ${ }^{44}$.

Lo anterior permitiría “una interpretación más amplia que podría abarcar otras categorías de

44 Ibíd. residentes a largo plazo"45, y que el residente tenga el derecho a regresar a su país de acogida, así no tenga formalmente la ciudadanía.

El Comité internacional sobre la eliminación de todas las formas de discriminación racial también ha llamado la atención para que se quiten “las posibles barreras que puedan impedir la naturalización a los residentes de larga data o permanentes" 46 .

\subsection{Xenofobia como manifestación contemporánea del trato discriminatorio}

Hoy día es aceptado, de forma mayoritaria, que la no discriminación por motivos raciales constituye un mandato de ius cogens, ¿por qué entonces no expandir tal restricción a la discriminación que se produce por el origen nacional de los inmigrantes? En efecto, los principales instrumentos internacionales de protección al incluir la cláusula de no discriminación reúnen en una misma norma la prohibición de discriminar ya sea por razones raciales o de origen nacional ${ }^{47}$. Aunque en el texto de la Convención internacional para la eliminación de todas las formas de discriminación racial se descartó expresamente de su competencia el trato diferenciado a extranjeros, su Comité de seguimiento ha suavizado esta restricción.

\footnotetext{
45 lbíd.

46 Comité internacional sobre la eliminación de todas las formas de discriminación racial. Recomendación general No. 30 de 2004.

47 Ver DUDH, PIDCP y PIDESC en su artículo 2
} 
En 2004, el Comité intentó darle un mayor alcance a la discriminación cometida por los Estados contra los no-nacionales. Es importante destacar que este pronunciamiento se nutrió de los debates de la Conferencia mundial de Durban (Sudáfrica) sobre el racismo, la discriminación racial, la xenofobia y las formas conexas de intolerancia, realizada en el año 2001. En tal sentido, el Comité hace público que en la Declaración de Durban se "reconoció que la xenofobia contra los no nacionales, en particular los migrantes, los refugiados y los solicitantes de asilo, constituía una de las principales fuentes del racismo contemporáneo, y que las violaciones de los derechos cometidas contra los miembros de esos grupos se producen ampliamente en el contexto de prácticas discriminatorias, xenófobas y racistas" 48 .

Dicha Declaración es valiosa, además, en la medida que permitiría aproximar la raza y la nacionalidad como motivos equiparables -e igualmente reprochables- de las conductas discriminatorias. Es posible advertir cómo el criterio de nacionalidad, más allá de una designación formal y legal conferida por el Estado, responde a criterios de identidad y pertenencia ${ }^{49}$, lo cual

48 Declaración de Durban, párrafo 16. Reiterado en el Comité para la eliminación de todas las formas de discriminación racial, Recomendación general No. 30 de 2004.

"nationality is a legal bond having as its basis a social fact of attachment, a genuine connection of existence, interest and sentiments, together with the existence of reciprocal rights and duties. It may be said to constitute the juridical expression of the fact that individual upon whom it is conferred ... is in fact more closely connected with the population of the State conferring nationality than with that of any other State. Conferred by a State, it only entitles that State to exercise protection vis-a-vis another State, if it constitutes a translation into juridical terms of the individual's connection with the State which has made him nacional" Esta doctrina del vínculo efectivo (effective link) fue presentada por la Corte Internacional de Justicia: Liechtenstein v. Guatemala, 1955. Reiterada a su vez por el Tribunal Ad Hoc de la lo acerca al concepto de raza. Siendo así, sería igual de censurable discriminar por razones de raza o nacionalidad, lo cual autorizaría cuestionar el trato diferenciado dado a los extranjeros, incluso cuando han entrado de forma ilegal al país receptor.

De acuerdo con el Comité, “los Estados Partes se obligan a garantizar la igualdad entre los ciudadanos y no ciudadanos en el disfrute de esos derechos en la medida reconocida en el derecho internacional" ${ }^{50}$. Esta última afirmación podría, empero, conducirnos a un círculo vicioso. Si la prohibición de discriminación tan sólo implica que los Estados deben garantizar los derechos acordados convencionalmente, nos devuelve al escenario deficitario de protección del sistema universal de derechos humanos, en el que sólo se reconoce el derecho a salir y entrar al propio país, y se autorizan limitaciones importantes en otros derechos.

Es por ello que aún con los avances impulsados por los comités de seguimiento, el déficit de protección a la población migrante es palpable. El ordenamiento jurídico internacional aún tolera el enorme poder de los Estados para regular sus fronteras y determinar quién se encuentra regularmente en su territorio y quién no, y por ende, quién es sujeto pleno de derechos y quién sólo lo es potencialmente.

Antigua Yugoslavia: Prosecutor v. Zejnil Delalic, Zdravko Mucic, Hazim Delic y Esad Landzo (Celebici Camp), 1998.

Comité para la eliminación de todas las formas de discriminación racial. Recomendación general No. 30 de 2004. 


\section{LA HOSPITALIDAD UNIVERSAL}

En 1795, Kant publicó el breve pero poderoso texto Sobre la paz perpetua, en el que describe los consejos jurídicos para superar el estado de hostilidad permanente en que se encuentran los pueblos entre sí. Al cumplirse el $150^{\text {vo }}$ aniversario de la aparición de este ensayo, el mundo presenció el 24 de octubre de 1945 cómo las potencias vencedoras de la segunda guerra mundial fundaron la Organización de Naciones Unidas, organismo cuya razón de ser se centraba en materializar aquellas máximas proclamadas años atrás por el filósofo de Königsberg: mantenimiento de la paz y cooperación internacional, de conformidad con los principios de la justicia y del derecho internacional.

Kant explicó que el estado de paz entre los hombres que viven juntos no es un producto de la naturaleza, la cual es más bien un estado de guerra, es decir, un estado en el que, si bien las hostilidades no se han declarado, sí existe una constante amenaza. El estado de paz, por ende, debe ser instaurado por el esfuerzo conjunto y consciente de los seres humanos ${ }^{51}$. Aún más, es un deber moral en cabeza de toda persona salir de este estado, para entrar en un escenario legal en el que el ordenamiento jurídico pueda tener cabida. Solo así, el derecho cosmopolita -esa idea racional de una comunidad pacífica universal formada por todos los pueblos de la tierra que pueden establecer relaciones efecti-

51 Kant, Immanuel. Sobre la paz perpetua. Madrid: Tecnos, 1998, p.14. vas entre si ${ }^{152}$ - puede alcanzarse, y lograr la tan anhelada paz duradera.

En el breve ensayo Sobre la paz perpetua, Kant expone tres principios que habrán de fungir como artículos definitivos del derecho cosmopolita, y constituirán el marco básico de coordinación de una nueva comunidad pacífica universal, a saber: La constitución civil de todo Estado debe ser republicana (artículo 1); El derecho de gentes debe fundarse en una federación de Estados libres (artículo 2); El derecho cosmopolita debe limitarse a las condiciones de la hospitalidad universal (artículo 3).

Quisiera ahora concentrarme en el tercer y último artículo definitivo, el de la hospitalidad universal, el cual responde directamente al objeto de este texto: las migraciones internacionales. De entrada, impacta que Kant solo proponga tres artículos definitivos para lo que sería algo así como la "Constitución Global". Y más relevante aún es que el tercer artículo es el único que introduce un derecho subjetivo concreto, mientras que los dos primeros abordan temas más generales sobre la constitución de cada Estado y la forma en que deben asociarse.

El tercer artículo definitivo resume el trato básico que debe darse entre los ciudadanos de distintos países, en tanto seres humanos que necesariamente tienen que coexistir en un espacio de tierra limitado. Este derecho de visita que Kant define, en términos muy sencillos, como "el derecho a presentarse a la sociedad,

52 Kant, Immanuel. Metafísica de las costumbres. Madrid: Tecnos, 2008 (§62) p. 192. 
que tienen todos los hombres en virtud del derecho de propiedad en común de la superficie de la tierra" 53 y a no ser tratado como enemigo en tierras extranjeras ${ }^{54}$, es, a su vez, una poderosa máxima de comportamiento y cooperación internacional.

De hecho, es el propio filósofo prusiano quien advierte que sólo así, permitiendo el libre tránsito de las personas por el globo terráqueo, es posible que partes alejadas del mundo puedan establecer relaciones pacíficas, que se conviertan finalmente en legales y públicas, "pudiendo así aproximar al género humano a una constitución política" ${ }^{\prime 5}$.

Y a partir de ello es que desarrollaré la siguiente tesis: el flujo libre de personas entre los Estados es indispensable como condición de posibilidad para que comiencen a entablarse relaciones sociales que progresivamente -al ir reconociendo al otro en su diferencia- deriven en auténticos compromisos jurídicos, materializados en normas de derecho público, que concluyan en la formación del ciudadano global.

Interactuar con el otro es un requisito para reconocer al extraño y concebirlo como un sujeto de derechos con quien sí es posible entablar relaciones horizontales. Solo cuando se incluye al otro, respetando al tiempo su diferencia cultural, es viable pensar en un nuevo modelo

53 Kant, Immanuel. Sobre la paz perpetua. Madrid: Tecnos, 1998, p. 27

54 Idea especialmente curiosa para un pensador del perfil de Kant, de quien se dice nunca abandonó su natal pueblo de Königsberg (hoy Kaliningrado, Rusia)

Kant, Immanuel. Sobre la paz perpetua. Madrid: Tecnos, 1998, p. 28 de pertenencia, determinado por las relaciones intersubjetivas en el marco de un sistema democrático.

\section{A. El colonialismo es incompatible con un orden global en paz}

La primera gran idea que se desprende del tercer artículo definitivo se formula de manera negativa respecto al derecho a la libre circulación: el extranjero no goza del derecho de huésped (para esto sería preciso un contrato especialmente generoso), sino de un simple derecho de visita, porque lo contrario ha servido como excusa para que las grandes potencias mercantiles conquisten y sometan a los pueblos.

En efecto, Kant observa con recelo cómo el derecho de tránsito - defendido por reconocidos publicistas clásicos como Francisco de Vitoriaterminó por legitimar a las potencias occidentales de su época, en un afán expansionista que los llevó a introducir tropas en territorios lejanos, "bajo el pretexto de establecimientos comerciales, y con las tropas introdujeron la opresión de los nativos, la incitación de sus Estados a grandes guerras, hambres, rebelión, perfidia y la letanía de todos los males que afligen al género humano"56.

Kant es un agudo crítico de la conducta de las potencias europeas de aquel entonces, y desnuda magistralmente los pretextos que argüían los imperios de la época para aprovecharse del derecho al libre tránsito internacional y someter pueblos extranjeros: "todo esto para potencias

56 Ibíd. p. 28. 
que quieren hacer muchas cosas desde su piedad y pretenden considerarse como elegidas dentro de la ortodoxia, mientras beben la injusticia como agua"57:

“... aunque aparentemente sean suficientes las razones que se utilizan para justificar que la violencia redunda en beneficio del mundo: sea por la cultura de los pueblos incultos, sea para limpiar el propio país de hombres corrompidos y por ello la esperanza de mejorarlos, a ellos mismos o a sus descendientes, en otra parte del mundo; porque todos esos propósitos, presuntamente buenos, son incapaces de lavar las manos de injusticia en los medios que se emplean para ello." 58

Como consecuencia de lo anterior, Kant limita la toma de posesión en las tierras recién descubiertas a dos estrictas condiciones: (i) que los colonos se instalen de forma tal que no perjudiquen al pueblo nativo en el uso de su terreno; y (ii) que actúen de buena fe, es decir, sin aprovecharse de la ignorancia de los pobladores en lo que se refiere a la cesión de las tierras ${ }^{59}$.

Al tiempo que critica la actitud hostil de los supuestos Estados "civilizados" de Occidente, Kant exalta la sabía postura de China y Japón al permitir exclusivamente el derecho de tránsito -y de manera controlada ${ }^{60}$ - de los extranjeros

57 Ibíd. p. 30.

58 Kant, Immanuel. Metafísica de las costumbres. Madrid: Tecnos, 2008 (§62) p. 194.

59 Ibídem

60 "China y Japón, que habían tratado con semejantes huéspedes, han permitido sabiamente el acceso pero no la entrada, en el caso de China, y sólo un acceso limitado a un único pueblo europeo, los holandeses, en el caso de Japón, a los que, además, excluyen de europeos, lo que les permitió resistir los ambiciosos embates colonialistas de las empresas intercontinentales del mercantilismo del siglo XVIII.

Esta delimitación del alcance del derecho de visita pone en evidencia que Kant no fue un simple pensador utópico y romántico. Su observación crítica del imperialismo ${ }^{61}$ puesto en práctica por las potencias europeas, lo llevó a restringir el principio de hospitalidad universal al derecho de visita, en aras de defender la libertad e independencia de los pueblos del mundo que caían presa de los colonizadores europeos, quienes argüían estar amparados por el derecho natural a la libre circulación internacional.

Sin embargo, habría que precisar que esta restricción a la libertad de circulación ha de ser proporcional a la magnitud de la amenaza que signifique el cruce de fronteras. Específicamente, Kant recomendaba a los pueblos de Oriente y de América restringir la entrada y permanencia de los agentes comerciales europeos y de sus tropas, con lo que se pone en evidencia que la limitación de la hospitalidad tiene un objetivo y un sujeto concreto: Ios Estados deben ser especialmente celosos de sus fronteras cuando del otro lado quienes amenazan entrar y dominar son imperios militares o económicos.

la comunidad de nativos, como a prisioneros". Kant, I. Sobre la paz perpetua, p. 30.

61

El imperialismo racional ha sido defendido por la corriente liberal antipluralista, que clasifica a los pueblos entre naciones civilizadas y pueblos bárbaros, en cuyo propio interés se justificaría la colonización y la pedagogía de parte de los Estados liberales desarrollados. Ver Simpson, Gerry. Two Liberalisms. EJIL, vol. 12, 2001. 
Pero los Estados deben bajar la guardia cuando quienes cruzan los bordes son grupos de ciudadanos sin intereses de imperio. No debemos confundirnos, pues como veremos a continuación, Kant era efectivamente un entusiasta defensor de la libre circulación de los individuos, y es en este aspecto donde podremos contemplar el valor y la extensión real de su aporte.

\section{B. Las personas inevitablemente existen en interdependencia dado el mundo compartido en el que viven}

La doctrina del derecho kantiana hace referencia a un sistema integrado por distintos grados de ordenamientos, estrechamente relacionados entre sí. De tal manera que, con tal de que a una de estas tres formas de estado jurídico (derecho político, derecho de gentes y derecho cosmopolita) "le falte el principio que restringe la libertad externa mediante leyes, el edificio de las restantes queda inevitablemente socavado y acaba por derrumbarse"62. Este efecto dominó, en el que una conducta individual repercute en la generalidad, también se evidencia en la relación entre los hombres, así se encuentren en partes alejadas del globo.

La naturaleza nos ha encerrado a todos dentro de los límites determinados de la esfera planetaria, y como la posesión del suelo sobre el que puede vivir un habitante de la tierra sólo puede pensarse como posesión de una parte de un determinado todo, por tanto, como una parte sobre la que cada uno de ellos tiene originariamente

62

Kant, Immanuel. Metafísica de las costumbres. Madrid: Tecnos, 2008 (§43) p. 140. un derecho, todos los pueblos originariamente tienen una vida entrelazada por la posesión común del suelo, pero no están aún en comunidad jurídica de la posesión (communio).

En este aspecto, Kant se distancia de la postura liberal clásica que concibe al ser humano desde el atomismo individual y egoísta del estado de naturaleza como un ser humano aislado y liberado de todos sus lazos comunitarios, afrontando cada uno la desprotección, la desnudez y el sufrimiento sin socorro ${ }^{63}$. Por el contrario, y habiendo avanzado en el establecimiento de una comunidad más o menos estrecha entre los pueblos de la tierra, el filósofo prusiano asegura que "la violación del derecho en un punto de la tierra repercute en todos los demás"64.

Precisamente, el contexto presentado por el fenómeno migratorio es revelador al respecto. Como se analizó al comienzo de este escrito, los flujos migratorios en la actualidad representan un desafío internacional por los millones de extranjeros que residen en países ajenos, los costos de los controles fronterizos y los intereses en juego. Dadas estas características, es muy cierto que la violación masiva de derechos que obliga a un pueblo a desplazarse entre las fronteras internacionales, es un evento que debe interesar prioritariamente a la comunidad internacional.

Presenciamos a diario cómo la distribución de los seres humanos en el espacio finito del globo terráqueo se vuelve cada vez más ajustada.

63 Carrillo. Óp. cit., p. 105.

64 Kant, Immanuel. Sobre la paz perpetua. Madrid: Tecnos, 1998, p. 30 
Desde una aproximación pesimista a la condición humana ${ }^{65}$, Kant advierte que la simple presencia en el estado de naturaleza de otro ser, es de por sí ya una amenaza para mi existencia. Desde este punto de vista, el vecino no me puede ser indiferente, todo lo contrario, es un factor de riesgo latente para mi proyecto de vida en el estado de naturaleza.

Sin embargo, desde otra perspectiva más alentadora, la existencia compartida de los seres humanos sobre la tierra también ha servido para la configuración de un estado de sociabilidad tenue, suficiente para que se origine una comunidad de interacción física a la que Kant llamó comercio (commercium).

Por ambas razones, Kant invita a que todas las personas que estén en la posibilidad material de afectarse mutuamente se reúnan en torno a una constitución civil común ${ }^{66}$. ¿Cómo dar este paso?, ¿qué característica, condición o cualidad tendría la fuerza suficiente para crear unos vínculos de identidad común capaces de convocar a las personas como ciudadanos del mundo? En el siguiente apartado esbozaré una propuesta de solución a este interrogante. Mientras tanto, concluyo esta sección afirmando que la interdependencia a la que estamos necesariamente llamados los seres humanos debido al lugar común que compartimos como hogar, y ante

65 No olvidemos que Kant comparte con Hobbes una visión antropológica pesimista, según la cual los hombres son egoístas y conviven en un estado de constante zozobra y miedo del otro.

Friedrich, Carl J. The Ideology of the United Nations Charter and the Philosophy of Peace of Immanuel Kant 1795-1945. The Journal of Politics. Vol. 9, No. 1 (Feb., 1947), pp. 10-30. Cambridge University Press on behalf of the Southern Political Science Association Stable. Recuperado el 10 de noviembre de 2011 en http://www.jstor.org/stable/2125857, p.21. la zozobra que nos produce vivir en el estado de naturaleza junto a los otros, no se resuelve por los lazos de la sociabilidad tenue que genera el comercio entre pueblos. Es preciso dar el paso hacia la conformación de una Constitución civil común que consolide un estado de paz duradera.

\section{La libre circulación plena como prerrequisito para la configuración de un modelo de ciudadanía global}

La Constitución cosmopolita es el escenario último de la doctrina del derecho público. Hemos visto cómo los imperios han abusado históricamente del derecho a la libre circulación para aprovecharse de la hospitalidad de los pueblos receptores, e irrumpir violentamente mediante tropas o emporios mercantiles. Pero también hemos advertido cómo la finitud del globo terrestre nos obliga a convivir y a entablar relaciones tenues, materializadas a través del comercio internacional.

La última reflexión que Kant aporta -pero a su vez la que sintetiza las discusiones anteriormente formuladas- y que quisiera desarrollar con la ayuda del filósofo contemporáneo Jürgen Habermas, es la confianza en que la libertad plena de circulación permitirá desencadenar un proceso a través del cual "puedan establecerse relaciones pacíficas entre partes alejadas del mundo, relaciones que se convertirán fácilmente en legales y públicas, pudiendo así aproximar al género humano a una constitución cosmopolita" 67 .

67 Kant, Immanuel. Sobre la paz perpetua. Madrid: Tecnos, 1998, p. 28. 
En efecto, la libre circulación plena internacional es la clave para superar los estrechos marcos en los que el concepto de Estado-nación ha encerrado a la ciudadanía, con la cuestionable premisa de que las naciones comparten una cultura homogénea que las identifica y las diferencia de cualquier otro pueblo. Bajo este postulado, el ciudadano solo está obligado a la lealtad con su Estado-nación y resulta absurdo concebir un modelo de "ciudadano del mundo".

Pero si uno logra ver a sus adversarios no como ineludiblemente extraños ni monstruos, sino como personas que comparten con nosotros ciertos fines y metas generales, es dable lograr la disminución de la ira y dar inicio al intercambio racional ${ }^{68}$. Para ello, para poder empezar a entender al otro más que como una constante amenaza a mi integridad, la libertad de circulación es fundamental en tanto que nos aproxima al extraño, y evita que el extranjero, por su desconocimiento, se convierta en un objeto de temor. Saltar sobre los muros y cruzar las fronteras es el mínimo psicológico y jurídico sin el cual ni siquiera es posible reconocer al otro e intercambiar palabras, y mucho menos concebir relaciones extrajurídicas entre los pueblos del mundo.

¿Qué queda después de derrumbar las fronteras? Sostengo que la libre circulación abre paso a un proceso gradual de reconocimiento e inclusión del otro, que terminará llevándonos hacia un nuevo modelo de ciudadanía global. Pero ¿qué unirá a los hombres sin fronteras para que sean capaces de pactar una constitución civil

68 Ibíd., p. 93. común? La respuesta está en el modelo de solidaridad abstracta presentada por Habermas. Para explicar este punto, presentaré en primer lugar el modelo de nación étnica que desde las revoluciones liberales de hace doscientos años ha reivindicado la idea de un imaginario cultural para identificar al nacional del extranjero. Luego, abordaré el nuevo modelo de cohesión social.

\section{EL MODELO CLÁSICO DE NACIÓN ÉTNICA}

Según la comprensión mayoritariamente aceptada, "Estado" es un concepto definido jurídicamente que en el orden material hace referencia a un poder estatal soberano tanto interna como externamente; en términos espaciales, se refiere a un territorio claramente delimitado; y, socialmente, a la totalidad de los miembros, es decir, al "pueblo propio de un Estado" (Staatsvolk). La dominación estatal se establece en formas propias del derecho positivo, y el "pueblo propio de un Estado" constituye el portador del ordenamiento jurídico restringido al ámbito de validez del territorio estatal y se reconoce por la expresión de identidad histórica común ${ }^{69}$.

De acuerdo con esta idea que surgió partir de las revoluciones de finales del siglo XVIII, Estado y nación se fundieron formando el "Estado nacional". Esta definición de la población de un Estado a partir de una identidad cultural compartida ha sido de vital importancia para afianzar un sentimiento de pertenencia común,

69 Habermas, Jürgen. La inclusión del otro: estudios de teoría política. Barcelona: Paidós, 1999, p. 83. 
necesario, a su vez, para la consecución de un compromiso firme con las instituciones del Estado y un acatamiento voluntario del orden jurídico interno. Para asegurar la creencia de una identidad común que garantice esta cohesión de la población, el Estado ha recurrido principalmente a dos herramientas ${ }^{70}$ : la evocación de un pasado común y la pertenencia a un grupo humano racial y/o culturalmente homogéneo ${ }^{71}$.

La continuidad entre una historia común y un presente que definen a un pueblo es uno de los principales recursos a los que acude el Estado, el cual tiene poderosos efectos sobre el comportamiento individual y, así, “[...] el pasado es una forma en virtud de la cual las personas son persuadidas para que actúen en el presente de maneras que de otro modo no harían"72. La membresía nacional, edificada sobre una supuesta identidad cultural homogénea, tiene entonces un efecto psicológico y político poderoso en sus integrantes, el cual moldea el comportamiento cívico; y a nivel jurídico, permite clasificar a las personas y definir tan solo a algunos de ellos - los nacionales, por oposición a los extranjeros- como sujetos de derechos y de privilegios especiales, en tanto ciudadanos. Ello

70 Ariza y Barbero. Óp. cit., p. 42.

71 Bauman señala que la construcción de identidad involucra tanto objetivos restaurativos como productivos. Los primeros se refieren principalmente a la invocación de la tierra y la sangre como elementos evocadores de un origen y un paso común que proporcionaría los cimientos de la identidad comunitaria. Por su parte, los elementos productivos se relacionan ante todo con la generación del sentimiento patriota o la identificación como miembro de un Estado-nación (Bauman, Zygmunt. "Soil, Bllod and Identity". The sociological review 40(4), 1992, p.696)

72 Wallerstein, Immanuel. "The Ideological Tensions of Capitalism: Universalism versus Racism and Sexism". En: Etienne Bailbar e Immanuel Wallerstein (eds.). Race, Nation, Class: Ambiguos Identities. London: Verso, 1991, p. 78. trae las consecuencias nefastas que ya se expusieron en el capítulo II: un mundo que construye el catálogo de derechos de las personas diferenciando entre categorías que obedecen a su estatus de regular o indocumentado en el país de acogida.

\section{Nuevo modelo de ciudadanía solidaria}

Somos conscientes de la necesidad de superar el modelo de nación étnica, mediante el cual el Estado y la nación se fundieron en lo que conocemos hoy día como Estados nacionales, pero no podemos simplemente pretender abolir el sentimiento nacional y esperar que las personas tengan la empatía suficiente para hacerse solidarios con quien sufre al otro lado del océano. Para lograr la movilización política de los ciudadanos se precisa una idea con fuerza capaz de crear convicciones y de apelar al corazón y al alma de una manera más enérgica que las nociones de soberanía popular y derechos humanos. Este componente psicológico -tal y como lo denomina Linda Bosniak al referirse a las acepciones de ciudadanía - lo brindaba la idea de nación étnica. Es preciso buscar ahora un reemplazo, al menos igual de fuerte.

Y es aquí donde Habermas nos presenta su aporte mayúsculo. Este pensador nos invita a repensar la pertenencia a la nación fundada, ya no como un vínculo de solidaridad entre personas a partir del imaginario de una supuesta identidad cultural común, sino desde una nueva forma de cohesión social: 
La ciudadanía democrática -en el sentido de citizenship- establece una solidaridad entre extraños comparativamente abstracta y, en cualquier caso, mediada jurídicamente; y este modo de integración social que surge por primera vez con el Estado nacional se lleva a cabo mediante la forma propia de un contexto comunicativo que interviene hasta en la socialización política. Esto depende, ciertamente, de la satisfacción de importantes requisitos funcionales que no cabe realizar fácilmente por medios administrativos. ${ }^{73}$

En otras palabras, esta propuesta defiende un vínculo de solidaridad abstracto, en tanto que no obedece a patrones culturales sustanciales para unir a una comunidad, sino a un contexto comunicativo en el que es viable un nuevo proceso de socialización en torno a la idea de pertenencia a un régimen democrático. Lo que une a una nación de ciudadanos -en contraposición a lo que ocurre en una nación étnica (Volksnationen)- no es un sustrato previo, sino un contexto, compartido intersubjetivamente, de entendimiento posible ${ }^{74}$.

Con ello es factible defender un "patriotismo constitucional" a partir del cual los ciudadanos se identifiquen con los principios de la propia constitución como una conquista en el contexto de la historia de su país y, al mismo tiempo, conciban la libertad de la nación de una manera universalista ${ }^{75}$. Visto desde una perspectiva actual, resulta además elogiable el hecho de

73 Habermas, Jürgen. La inclusión del otro: estudios de teoría política. Barcelona: Paidós, 1999, p. 141.

74 lbíd., p. 88. que en el escenario de la ilustración, algunos filósofos partidarios de la revolución francesa, entre los cuales se encontraba Kant, lograsen armonizar en su particular idea de nación dos sentimientos que hoy nos parecen tan contradictorios: por un lado, el amor a la patria, y, por otro, el amor a la humanidad ${ }^{76}$. En este sentido, Kant antepuso un modelo de reflexión crítica y objetiva que conceptúa a la razón como la prueba fehaciente de que todos los seres humanos pertenecen, sin discriminación alguna, a una misma familia: el género humano ${ }^{77}$. Con ello, el compromiso del buen ciudadano no se limitaba a la lealtad para con sus nacionales.

\section{CONCLUSIONES}

Bien podrían algunos argumentar que el cultivo de la humanidad a partir de la interacción que permite el libre tránsito internacional de personas no es más que una quimera producto de disquisiciones filosóficas, pues es ilusorio asumir que las personas olvidarán sus identidades grupales para formar parte de una masa amorfa llamada humanidad.

En respuesta, reitero que la propuesta de este nuevo modelo de cohesión social no pretende llegar al extremo de renunciar a nuestras particulares inclinaciones e identificaciones, ya sean nacionales, étnicas o religiosas ${ }^{78}$; más bien, la

76 Ibíd., p. 84.

77 García Morente, M. La filosofía de Kant. Una introducción a la filosofía. Madrid: Espasa-Calpe, 1986, p. 110.

78

Como denuncia Martha Nussbaum "Adam Smith cometió un grave error cuando objetó el estoicismo sobre esas bases; y los críticos modernos de las concepciones kantianas y de la llustración emparentadas 
apuesta por el cultivo de la humanidad debería llevarnos a trabajar para hacer que "todos los seres humanos formen parte de nuestra comunidad de diálogo y de preocupaciones, mostrando respeto por lo humano dondequiera que se dé, y permitiendo que ese respeto marque los límites de nuestras políticas nacionales 0 locales"79.

¿Cómo se comportará específicamente este nuevo ciudadano global?, ¿qué otros derechos además de la libre circulación plena serán defendidos por esta ambiciosa constitución global? Son preguntas que superan los propósitos de este documento. Pero estoy convencido de que la confianza depositada en la libre circulación plena, como el punto de inicio que ponga en marcha el engranaje de un nuevo proceso de intercambio social -con respeto por la alteridad del otro-, es una apuesta lo suficientemente revolucionaria y llamativa para guiarnos hacia un nuevo pueblo global, que así como experimenta las particularidades locales, reconoce el llamado de la humanidad en todo otro individuo.

En resumen, hemos observado entonces cómo cada día se hace más evidente la insuficiencia del sistema universal de derechos humanos para proteger a los migrantes. Su principal problema es que sigue atado al modelo de nación étnica, lo que lo lleva a tolerar la calificación de las personas con fundamento en su condición migratoria. De acuerdo con este criterio, es

con el estoicismo cometen un error similar cuando las acusan de descuidar las diferencias entre los grupos humanos". Nussbaum, Martha. El cultivo de la humanidad. Una defensa clásica de la reforma en la educación liberal. Barcelona: Paidós, 2005, p. 88. natural diferenciar abiertamente al nacional del migrante, con la consecuente pérdida de derechos que esto acarrea para el segundo.

Es más, el sistema internacional ni siquiera reconoce el derecho a visitar cualquier otro país, salvo el propio. Debido a este discurso incompleto, miles de personas son condenadas a su propia suerte, mientras intentan cruzar mares, ríos y desiertos. Su único delito: haber nacido en un país en desarrollo. Es hora de replantear el derecho a la libre circulación, y señalar lo absurdo que resulta el derecho a salir del propio Estado sin que ningún otro país esté en la obligación de dejarle entrar.

A la luz de Kant y Habermas, hemos reivindicado la importancia profunda que tiene garantizar la libre circulación plena para la consecución de un orden global en paz duradera. Sólo así, permitiéndose la libre circulación internacional, es posible expandir el concepto de ciudadanía ${ }^{80}$ en el orden cosmopolita, para reconocer la dignidad de todo ser humano independientemente de las contingencias de su origen nacional y la importancia del individuo para un modelo constitucional global ${ }^{81}$.

80 Un fenómeno similar ya ha venido ocurriendo en los territorios nacionales, donde el concepto de ciudadanía fue integrando progresivamente sujetos que en un principio no se aceptaban como ciudadanos: "On the whole, the history of liberalism reflects a tendency to expand both the definition of the public sphere and the requirements of equal treatment. In the United States today, for example, in contrast to earlier times, both public agencies and private corporations may not legally exclude women simply because they are women (although private clubs still may). A white shopkeeper may no longer exclude blacks from his store (although he may exclude them from his home). I think these recent developments, like the earlier extension of the franchise, reflect something fundamental about the inner logic of liberalism. The extension of the right to immigrate reflects the same logic: equal treatment of individuals in the public sphere". Aliens and Citizens, p. 268.

81 "The third definitive article suggested by Kant addresses itself to what Kant calls the jus cosmopoliticum or law of world citizenship. It is highly 
En este sentido, abrir las fronteras físicas es también derrumbar muros mentales de prejuicios e ignorancia que terminan alimentando la sospecha y el odio hacia el extraño. Es acercarnos al otro, respetando su alteridad, para entablar relaciones sociales y potencialmente jurídicas. Cuando las fronteras caigan será más fácil identificarnos como miembros de la gran familia humana.

\section{Bibliografía}

\section{i. Normas internacionales:}

ONU. Carta de San Francisco - fundacional de las Naciones Unidas (1945).

Declaración Universal de los Derechos Humanos (1948).

Convención internacional sobre la eliminación de todas las formas de discriminación racial (1965).

Pacto Internacional de Derechos Civiles y Políticos (1966).

Pacto Internacional de Derechos Económicos, Sociales y Culturales (1966).

Convención sobre el Estatuto de los Refugiados (1951) y su Protocolo Adicional (1967).

significant that Kant, unlike the Covenant of the League of Nations and the United Nations Charter, insists upon the importance of making the individual a member of the world order". Friedrich. Óp. cit., p. 28.
Convención internacional sobre la protección de los derechos de todos los trabajadores migratorios y sus familiares (2005).

\section{ii. Libros y artículos académicos:}

Aleinikoff, Alexander \& Chetail, Vincent (Ed.). Migration and International legal norms. The Hague: TMC Asser Press, 2003.

Arango, Rodolfo. "Realizando la Justicia Social”. En: Cortés, Francisco y Giusti, Miguel. Justicia global, derechos humanos y responsabilidad. Bogotá: Siglo del Hombre Editores, 2007.

Ariza, Libardo (Ed). Ciudadanía sin Nación. Bogotá: Siglo del Hombre Editores, 2010.

Benhabib, Seyla. The rights of Others. Aliens, Residents and Citizens. Conference on "Migrants, Nations and Citizenship". CRASSH, July 5-7, 2004.

Butler, Judith \& Chakravorty Spivak, Gayatri. Who sings the nation-state? Calcuta: Seagull, 2007.

Byer, Michael. "Conceptualising the relationship between jus cogens and erga omnes rules". Nordic Journal of International Law. Vol. 66, 1997, pp. 211- 239.

Cançado Trindade, Antonio. “Derecho internacional de los Derechos Humanos, Derecho Internacional de los Refugiados y Derecho Internacional Humanitario: Aproximaciones y convergencias". El Derecho Internacional de los Derechos Humanos en el siglo XXI. Jurídica de las Américas, 2009, pp. 187-269. 
Carens, Joseph H. “Aliens and Citizens: The Case for Open Borders". The Review of Politics, Vol. 49, No. 2 (1987), pp. 251-273. Cambridge: Cambridge University Press for the University of Notre Dame du lac on behalf of Review of Politics.

Carens, Joseph H. "Realistic and Idealistic Approaches to the Ethics of Migration". International Migration Review, Vol. 30, No. 1. Special Issue: Ethics, Migration, and Global Stewardship (1996), pp. 156-170. New York: Center for Migration Studies.

Carrillo, Lucy. "El concepto kantiano de ciudadanía". Estudios Filosóficos n 42. Medellín: Universidad de Antioquia, 2010, pp. 103-121.

Castles, Stephen \& Miller, Mark J. The Age of Migration: International population movements in the modern world. London: Gilford Press, 2009.

Chataway, Teresa. Cosmopolitical Citizenship: Seeing the World Through the Eyes of Others. Content downloaded/printed from HeinOnline (http://heinonline.org) Sun, Nov. 13.

Chetail, Vincent (Ed.). Globalization, Migration and Human Rights: International law under review. Bruxelles: Bruylant, 2007.

Dauvergne, Catherine. "Sovereignty, Migration and the Rule of Law in Global Times". The Modern Law Review, 2004.

Fitzpatrick, Joan. "The Human Rights of Migrants". En: Aleinikoff, T. Alexander y Chetail, Vincent (eds.) Migration and International Legal Norms. The Hague: Asser Press, 2003.

Friedrich, Carl J. "The Ideology of the United Nations Charter and the Philosophy of Peace of Immanuel Kant 1795-1945". The Journal of Politics, Vol. 9, No. 1 (Feb., 1947), pp. 1030. Cambridge: Cambridge University Press on behalf of the Southern Political Science Association Stable. Recuperado en http:// www.jstor.org/stable/2125857.

Habermas, Jürgen. La inclusión del otro: estudios de teoría política. Barcelona: Paidós, 1999.

Habermas, Jürgen. "The concept of human dignity and the realistic utopia of Human Rights". Metaphilosophy. Journal compilation. USA: LLC and Blackwell Publishing Ltd., 2010.

Kant, Immanuel. Metafísica de las costumbres. Madrid: Tecnos, 2008.

Kant, Immanuel. Sobre la paz perpetua. Madrid: Tecnos, 1998.

Kaufman, Gustavo Ariel. Dignus Inter Pares: Un análisis comparado del derecho antidiscriminatorio. Buenos Aires: Abeledo Perrot, 2010.

Kennedy, David. The International Human Rights Movement: Part of the Problem?. Recuperado el 18 de mayo de 2011 en http://www.law. harvard.edu/students/orgs/hrj/iss15/kennedy.shtml. 
Llano Alonso, Fernando. El humanismo cosmopolita de Immanuel Kant. España: Dykinson, 2004. Recuperado en http:// site.ebrary.com/lib/bibliotecauniandessp/ Doc? $\mathrm{id}=10057521 \& \mathrm{ppg}=73$

Nafziger, James A. R. "The General Admission of Aliens under International Law". The American Journal of International Law, Vol. 77, No. 4 (1983), pp. 804-847. Washington: American Society of International Law.

Nifosi-Sutton, Ingrid. “The Power of the European Court of Human Rights to Order Specific NonMonetary Relief: a Critical Appraisal from a Right to Health Perspective". Harvard Human Rights Journal: Vol. 23.

Nussbaum, Martha C. El cultivo de la humanidad. Una defensa clásica de la reforma en la educación liberal. Barcelona: Paidos, 2005.

OIM. Informe sobre las migraciones en el mundo. El futuro de la migración: Creación de capacidades para el cambio. 2010.
Pécoud, Antoine and Guchteneire, Paul. "International Migration, Border Controls and Human Rights: Assessing the Relevance of a Right to Mobility". Journal of Borderlands Studies. Vol. 21, No. 1, 2006.

Quesada, Fernando. Ciudad y ciudadanía: senderos contemporáneos de la filosofía política. Madrid: Trotta, 2008.

Rajagopal, Balakrishnan. El derecho internacional desde abajo. El desarrollo, los movimientos sociales y la resistencia del tercer mundo. Bogotá: ILSA, 2005.

Satvinder, S. Juss. "Free Movement and the world order". International Journal of Refugee Law, vol. 16: 3, 289-335.

Steiner, Niklaus. International migration and citizenship today. New York: Routledge, 2009.

Velásquez, Marco. Freedom of Movement under the framework of regional integration processes in South America. Dissertation Submitted in fulfilment of the requirement for the Master in International Studies (MIS). Geneva, 2010. 


\begin{tabular}{|c|c|c|c|}
\hline Norma & \multicolumn{2}{|r|}{ Sujeto protegido } & Derechos y obligaciones \\
\hline $\begin{array}{l}\text { Declaración Univer- } \\
\text { sal de los Derechos } \\
\text { Humanos }\end{array}$ & \multicolumn{2}{|r|}{ Todo ser humano. } & $\begin{array}{l}\text { - Toda persona tiene derecho a circular libremente y a } \\
\text { elegir su residencia en el territorio de un Estado (art. } \\
\text { 13). } \\
\text { - Toda persona tiene derecho a salir de cualquier país, } \\
\text { incluso el propio, y a regresar a su país (art. 13). } \\
\text { - Toda persona tiene derecho a buscar asilo, y a disfrutar } \\
\text { de él, en cualquier país (art. 14). } \\
\text { - Toda persona tiene derecho a que se establezca un or- } \\
\text { den social e internacional que haga efectiva la DUDH } \\
\text { (Art. 28). }\end{array}$ \\
\hline \multirow{2}{*}{$\begin{array}{l}\text { Convención inter- } \\
\text { nacional sobre la } \\
\text { eliminación de } \\
\text { todas las formas } \\
\text { de discriminación } \\
\text { racial }\end{array}$} & \multirow{2}{*}{ 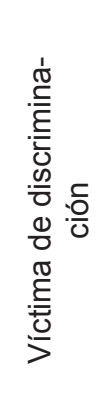 } & Extranjero & $\begin{array}{l}\text { - Proteger en contra de expulsiones colectivas, acceso a } \\
\text { la justicia, no discriminación policial (OG 30). } \\
\text { - Disfrutar de los derechos económicos, sociales y cul- } \\
\text { turales, sobre todo en las esferas de la educación, la } \\
\text { vivienda, el empleo y la salud (OG 30). } \\
\text { - Facilitar el acceso a la ciudadanía, especialmente para } \\
\text { los residentes de larga data (OG } 30) \text {. }\end{array}$ \\
\hline & & Nacional & $\begin{array}{l}\text { - Todos los derechos civiles y económicos, incluido el de- } \\
\text { recho de tomar parte en elecciones, elegir y ser elegido } \\
\text { (OG 30). }\end{array}$ \\
\hline \multirow{3}{*}{$\begin{array}{l}\text { Pacto Internacional } \\
\text { de Derechos Civiles } \\
\text { y Políticos }\end{array}$} & \multirow{2}{*}{ 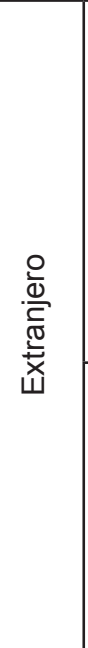 } & En situación irregular & $\begin{array}{l}\text { - Salir libremente de cualquier país, independiente de sus } \\
\text { motivos (art. } 12 \text { y OG 27). } \\
\text { obligación del Estado de expedir los documentos } \\
\text { de viaje necesarios. } \\
\text { - No ser arbitrariamente privado del derecho a entrar en } \\
\text { su propio país. } \\
\text { - No ser extraditado, deportado, expulsado o retirado de } \\
\text { otro modo, cuando hay razones de peso para creer que } \\
\text { existe un riesgo real de provocar un daño irreparable. }\end{array}$ \\
\hline & & En situación regular & $\begin{array}{l}\text { - Derecho a circular libremente por el territorio y a esco- } \\
\text { ger libremente en él su residencia (art. 12). } \\
\text { - Derecho a no ser expulsado, sino en cumplimiento de } \\
\text { una decisión adoptada conforme a la ley, y con sujeción } \\
\text { al debido proceso (art. 13). } \\
\text { - Adicionalmente, es sujeto de los otros derechos de la } \\
\text { Convención salvo regla expresa en contrario (OG 15). }\end{array}$ \\
\hline & & Nacional & $\begin{array}{l}\text { Todos los derechos de la Convención, incluyendo la par- } \\
\text { ticipación en la dirección de los asuntos públicos y el de- } \\
\text { recho a votar y ser elegido (art. 25). }\end{array}$ \\
\hline \multirow[t]{2}{*}{$\begin{array}{l}\text { Pacto Internacional } \\
\text { de Derechos Eco- } \\
\text { nómicos, Sociales y } \\
\text { Culturales }\end{array}$} & & Extranjero & $\begin{array}{l}\text { - Los países en desarrollo, teniendo debidamente en } \\
\text { cuenta los derechos humanos y su economía nacional, } \\
\text { podrán determinar en qué medida garantizarán los de- } \\
\text { rechos económicos reconocidos en el presente Pacto } \\
\text { a personas que no sean nacionales suyos (art. 2.3). } \\
\text { - Oportunidades de empleo para trabajadores migrato- } \\
\text { rios (OG 18.) }\end{array}$ \\
\hline & & Nacional & $\begin{array}{l}\text { Todos los derechos de la Convención, incluyendo el de- } \\
\text { recho al trabajo, seguridad social, educación. }\end{array}$ \\
\hline
\end{tabular}




\begin{tabular}{|c|c|c|c|}
\hline Norma & & Sujeto protegido & Derechos y obligaciones \\
\hline \multirow{2}{*}{$\begin{array}{l}\text { Convención inter- } \\
\text { nacional sobre la } \\
\text { protección de los } \\
\text { derechos de todos } \\
\text { los trabajadores } \\
\text { migratorios y sus } \\
\text { familias }\end{array}$} & \multirow{2}{*}{ 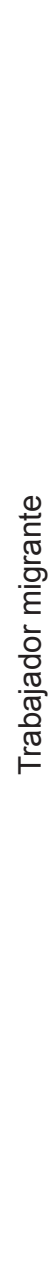 } & En situación irregular & $\begin{array}{l}\text { - Libre circulación: } \\
\text { o salir libremente de cualquier Estado y regresar al pro- } \\
\text { pio (art. 8). } \\
\text { - Otros derechos } \\
\text { Vida (9), prohibición de tortura, tratos crueles e in- } \\
\text { humanos (10), no esclavitud ni servidumbre (11), } \\
\text { libertad de pensamiento y religiosa (12), derecho } \\
\text { de opinión y libertad de expresión (13), no deten- } \\
\text { ción o prisión arbitraria (16), ser oídos ante un tri- } \\
\text { bunal competente (18), prohibición de medidas de } \\
\text { expulsión colectiva (22), igualdad en condiciones } \\
\text { de empleo con los nacionales }{ }^{82}(25) \text {, participar en } \\
\text { reuniones de sindicato (26), atención médica ur- } \\
\text { gente (28), acceso a la educación para sus hijos } \\
\text { (30). }\end{array}$ \\
\hline & & En situación regular & $\begin{array}{l}\text { - Incluye también los derechos previstos para los mi- } \\
\text { grantes en situación irregular. } \\
\text { - Libre circulación: } \\
\text { Libertad de movimiento en el territorio del Estado } \\
\text { de empleo y a escoger en él su residencia (art. } \\
\text { 39). } \\
\text { - Otros derechos: } \\
\text { Plenamente informados (37), ausentarse temporalmente } \\
\text { (38), establecer asociaciones y sindicatos (40), participar } \\
\text { en los asuntos públicos de su Estado de origen y a votar } \\
\text { y ser elegidos en elecciones celebradas en ese Estado } \\
\text { (41), orientación social planes de vivienda (43), unidad } \\
\text { familiar (44, 45), libertad de elegir su actividad remune- } \\
\text { rada (52), igualdad de trato respecto de los nacionales } \\
\text { de empleo en el ejercicio de esa actividad remunerada } \\
\text { (55), condiciones de trabajo y de vida de los trabajadores } \\
\text { migratorios y sus familiares de acuerdo con la dignidad } \\
\text { humana (art. } 70 \text { ). }\end{array}$ \\
\hline
\end{tabular}

82 Los trabajadores migratorios gozarán de un trato que no sea menos favorable que el que reciben los nacionales del Estado de empleo en lo tocante a remuneración y de:

a) Otras condiciones de trabajo, es decir, horas extraordinarias, horario de trabajo, descanso semanal, vacaciones pagadas, seguridad, salud, fin de la relación de empleo y cualesquiera otras condiciones de trabajo que, conforme a la legislación y la práctica nacionales, estén comprendidas en este término;

b) Otras condiciones de empleo, es decir, edad mínima de empleo, restricción del trabajo a domicilio y cualesquiera otros asuntos que, conforme a la legislación y la práctica nacionales, se consideren condiciones de empleo. 